\title{
Complicaciones Vasculares del Paciente Diabético
}

\author{
Rodolfo Alvarado-Herrera ${ }^{1}$
}

El pie diabético es la complicación más temida de los pacientes con el trastorno metabólico de la glucosa, ya que se puede presentar en cualquier momento de la evolución de la devastadora enfermedad, que casi invariablemente termina afectando todos los órganos de la economía. Voy a limitar este comentario a los trastornos de las extremidades inferiores. Dejaré de lado, por lo tanto, las no menos importantes patologías presentes en la enfermedad: la lesión renal, la coronariopatía y los trastornos oculares que afectan primordialmente la retina.

Con gran frecuencia tendremos que abordar el problema de los pies del diabético cuando ya se han complicado con la simultánea presencia de la poli-neuropatía y la infección. Ambas patologías pueden suceder aisladas o juntas, con isquemia o sin ella.

Un factor determinante en la deformidad de la extremidad, considerado actualmente de gran trascendencia, es la atrofia intrínseca de los delicados músculos del pie, consecuencia directa de la neuropatía motora. La atrofia muscular crea puntos de presión principalmente en las cabezas de los metatarsianos y las últimas falanges. La neuropatía sensitiva mantiene al paciente ignorante de la progresión de las lesiones compresivas y de las lesiones cortantes o perforantes de la piel, ocasionadas por innumerables objetos filosos o agudos que son, la mayoría de las veces, la causa directa de la entrada subcutánea de los gérmenes que provocan las infecciones. Otras lesiones de piel, frecuentes y muy importantes, son las ocasionadas por las micosis plantares e interdigitales. El corte de uñas y el "arreglo" de los pies hechos por el paciente o por los técnicos de los salones de belleza, siguen siendo una de las causas más frecuentes de la lesión dérmica que inicia la infección. La respuesta a la inflamación de origen neurogénico -en la que intervienen, entre otros, las neuro-quininas y que podríamos llamar "luz de alarma" para el enfermo- está casi abolida en los pies de los diabéticos, lo que constituye un factor más en la producción de las lesiones.

Conocida de todos los que estamos involucrados en el tratamiento de los pies del diabético, es la sui generis distribución de las lesiones vasculares oclusivas, que con mucho más frecuencia de lo que sucede en el enfermo arteriosclerótico puro, afecta las arterias en la región de la pierna, más allá de la

Cirujano vascular

Catedrático Universidad de Costa Rica. bifurcación de la poplítea, ya sea en la tibial anterior o en el tronco tibio-peroneo. La lesión obliterante se extiende principalmente a todo el tercio superior y medio del trayecto de las tres arterias: tibial anterior, tibial posterior y peronea. Vale la pena hacer hincapié en un hallazgo muy frecuente: encontrar la arteria pedia perfectamente permeable y capaz de recibir, sin ningún problema, un puente con vena safena que le restituya, totalmente, la circulación perdida al pie del diabético. Es importante también recordar lo que ha sido demostrado por el doctor Frank W. LoGerfo y otros insignes investigadores en este campo: que en más del noventa y cinco por ciento de los casos, el pie del diabético no sufre de microangiopatía. Este importante descubrimiento nos garantiza una excelente revascularidad cuando realizamos un puente arterial con anastomosis en la arteria pedia.

Actualmente no se concibe pasar por alto la exploración quirúrgica de los pacientes con problemas isquémicos, aún en aquellos casos en que la arteriografía no fuere capaz de demostrar vasos finales permeables. La decisión de operar está más bien condicionada a sí existe o no la posibilidad de conservarle al paciente su miembro inferior y su pie útiles para su deambular. El camino que se siga estará de acuerdo con el grado de necrosis que haya sufrido la extremidad y con la posible rehabilitación del enfermo. Se tendrá como referencia su estado general preoperatorio valorado a través de exámenes de laboratorio y de gabinete.

El control permanente de la salud de sus pies es una obligación del paciente y de sus familiares. A su vez, no se concibe el clínico que atiende diabéticos y que no hace una rutina estricta de revisión metódica y acuciosa de las extremidades de sus consultantes. Por desgracia -ocurre con frecuencia- el paciente pasa días o semanas con declarada infección y sin diagnóstico. El tratamiento del pie diabético es una disciplina múltiple y compleja, que involucra al clínico, al cirujano, a la enfermera, al paciente y a sus familiares.

El diabético con una infección en el pie es una emergencia que no puede esperar al cirujano que se encuentra de vacaciones. No se justifica siquiera que este paciente tenga que aguardar dos o tres días porque no hay campo en la sala quirúrgica para realizar el procedimiento que pueda salvarlo de una amputación. Un adecuado drenaje de todos los puntos sépticos, con resección del tejido obviamente necrótico, con amputaciones menores si son del caso, constituye la primera 
etapa del tratamiento que puede conservar viables las extremidades del enfermo. No existe absolutamente ninguna razón que pueda aducirse para "dejar para mañana" el drenaje y el desbridar un absceso. Para su desgracia, es corriente que el enfermo, no acuse dolor alguno. Esto ocasionará el equivocado proceder de algunos cirujanos que retrasan el drenaje de los pies afectados esperando, a veces, innecesarios exámenes preoperatorios. La progresiva destrucción de los tejidos podales del paciente diabético se agrava cada minuto. Un paciente sin neuropatía y que tuviera una lesión séptica del pie, por su dolor, no dejaría al cirujano atrasar el procedimiento más de veinticuatro horas, como sí sucede frecuentemente con el diabético cuya sensibilidad está muy disminuida, motivo por el que no valora en su real magnitud lo necesario de la pronta atención.

El drenaje plantar o del dorso del pie por un absceso, tiene que hacerse antes de realizar la cirugía para revascularizar el miembro. No debemos desbridar el tejido isquémico que no está necrótico y que no forma parte de la infección. Drenado y desbridado el pie, la cirugía puede esperar a que se haya controlado adecuadamente la infección, lo que se logra en cinco o seis días durante los cuales se usarán los antibióticos indicados. Después de haber restablecido la circulación al pie enfermo, se requiere una nueva valoración para hacer, si es pertinente, un procedimiento más que desbride los tejidos no viables y permita una pronta cicatrización.

El clínico, así como el cirujano -repetimos- están en la obligación de evaluar el estado circulatorio de los pies de todos los pacientes que se les presenten en consulta, pero sería imperdonable que no lo hicieran con el enfermo diabético. Por más característica que sea una úlcera neuropática, puede estar complicada con isquemia. Pulsos ausentes (tibial anterior o tibial posterior) deben iniciarnos en el camino de la cirugía para revascular el pie. Corrientemente este es el momento para indicar la arteriografía.

La visualización radiográfica de las arterias distales de la extremidad inferior, en un paciente con oclusión proximal de las arterias infrapoplíteas, no es una tarea fácil. No nos hemos acostumbrado, en Costa Rica, al uso de la arteriografía digital de sustracción, unas veces por falta de equipo y otras por desconocimiento de sus beneficios. El estudio de rayos $\mathrm{X}$ debe complementarse con el ultrasónico, que casi invariablemente nos demostrará la permeabilidad de estas arterias finales más allá de la oclusión, donde será fácil hacer una anastomosis vascular. Casi puede decirse que la respuesta "doppler" positiva en la arteria pedia nos obliga a una exploración quirúrgica, indistintamente del resultado del estudio angiográfico.

Estamos entonces listos para iniciar la cirugía vascular con anastomosis terminal en el pie, ya sea de la poplítea a la arteria pedia (el mejor procedimiento cuando es factible), o de la femoral a la pedia, o de alguna de esas dos arterias proximales a la tibial posterior (excepcionalmente la anastomosis se hará a la arteria peronea). Si el procedimiento vascular no logra restituir un pulso "lleno" en la arteria distal donde se realice la anastomosis, el resultado será de muy dudoso beneficio para el paciente, aunque constatemos la permeabilidad del puente con vena safena. En nuestro medio no se ha popularizado el puente (By-pass) que deja la safena in situ, principalmente por que los valvulotomos no han sido suficientemente buenos como para ser empleados sin el angioscopio que se usa de rutina en los países del norte. La inversión de la vena es una buena alternativa; pero, a no dudarlo, para un puente desde la femoral a la pedia, nada mejor que dejar la safena in situ. Personalmente no he tenido la oportunidad de participar en Costa Rica de un procedimiento de puente fémoro-pedio in situ, pero he sido informado de varios casos en los cuales esa ha sido la técnica seguida, tanto en el Hospital Dr. Rafael A. Calderón Guardia como en el Hospital San Juan de Dios. Esta técnica es una rutina (tres casos por semana) en los hospitales bostonianos Deaconess Medical Center y MGH, que recién tuve la suerte de visitar una vez más.

Vale la pena mencionar que los procedimientos de angioplastía proximal en la profunda -o en la poplítea-, si no se acompañan de un puente vascular, no lograrán salvar ningún pie con isquemia crítica, sepsis o necrosis. Como procedimientos aislados han dejado de practicarse en todos los centros médicos que he visitado, y no existe ninguna indicación actual para recurrir a ellos.

En los últimos veinte años estos procedimientos de puentes a las arterias del pie han logrado cambiar radicalmente las estadísticas de salvamento de las extremidades, principalmente en el paciente diabético. Hace aproximadamente trece años se realizó el primer puente distal a la arteria pedia en el Hospital Dr. R. A. Calderón Guardia. Actualmente en ese centro se han completado cerca de cien procedimientos. Sorprendentemente, en los otros hospitales, juntos todos, los casos no pasan de veinte. Esto demuestra la falta de comunicación existente entre los cirujanos encargados de este tipo de cirugía. Ha habido renuencia entre los angiólogos a la exploración de las arterias podales, cuando la arteriografía no ha detectado vasos permeables capaces de recibir la anastomosis del puente con vena safena. Recientemente, en la visita ya mencionada al Beth Israel Deaconess Medical Center, en Boston, tuve la oportunidad de conversar con el doctor Frank W. LoGerfo, sobre la dificultad que en nuestro medio teníamos para visualizar las arterias del pie en el paciente isquémico. La observación fue: "visualizadas o no, siempre realizamos una exploración que nos permita asegurar la posibilidad de revascularizar o que nos confirme la imposibilidad de hacerlo. Noventa por ciento de las veces el procedimiento es factible. En algunos casos prescindimos de la arteriografía".

Antes de entrar en el análisis de las amputaciones menores y mayores en los pies de los diabéticos, es justo mencionar que el panorama ha cambiado radicalmente con la creación de las clínicas del pie diabético, que funcionan en los tres principales hospitales de la capital. La atención que reciben los pacientes con problemas de miembros inferiores, por parte de las enfermeras especializadas, ha sido el mejor avance 
que he podido detectar. "Mucho cariño, mucha dedicación, mucha paciencia y constante desbridación" es el lema que ha logrado reducir el número de amputaciones en nuestro medio. Sufrimos en el entorno nacional por la falta del especialista en podiatría que solucione quirúrgicamente muchas de las causas iniciales de las úlceras del pie, quitando los puntos de presión, que por la neuropatía y la atrofia muscular se van produciendo progresivamente en el paciente diabético. Con frecuencia un adecuado zapato será el que salve una extremidad.

En nuestros hospitales la cirugía de osteotomías metatársicas para el paciente diabético se ve con escepticismo y preocupación, por la creencia de que la sepsis postquirúrgica en el pie diabético es difícil de evitar. La realidad es muy otra. De nuevo, en Boston, pude comprobar que ese tipo de cirugía se practica actualmente con excelentes resultados. Es cirugía de rutina para los diabéticos.

Pasaré a resumir algunas indicaciones que servirán como guía para iniciar un tratamiento de los pies con sepsis, isquemia o necrosis, otras de las obligatorias como el reposo absoluto, antibióticos, control de la glicemia, etc.

\section{Amputaciones Menores}

Nunca estará de más repetir que las amputaciones deben planearse cuidadosamente para dejar siempre suficiente tejido que haga factible la cicatrización y que conserve un pie funcional. Las amputaciones menores y el desbridamiento del pie séptico no son procedimientos que deban quedar, sin vigilancia, en las manos de residentes e internos carentes de la debida y comprobada excelencia para realizarlos. Las incisiones lineares de piel son a veces suficientes para desbridar y realizar una amputación menor.

En general, las amputaciones menores cerradas se harán después de corregir el déficit vascular del pie isquémico, o en los pacientes que, con adecuada circulación, tienen importante pérdida de tejido, como es frecuente en los que padecen las lesiones que acompañan a la úlcera neuropática. Insisto: la necesidad de que los procedimientos como osteotomías, resecciones óseas menores y plastías de las cápsulas articulares de los ortejos, se realicen con más frecuencia en nuestro medio, es indiscutible. El que no sea así, a pesar de que el número de diabéticos aumenta preocupantemente año con año, solo puede interpretarse como que hemos perdido el ritmo del progreso en el tratamiento de esta tan temida patología.

\section{Amputación Transmetatársica}

A pesar de los inconvenientes que para la estabilidad del pie puede significar una amputación transmetatársica, este procedimiento es necesario en un gran número de casos. $\mathrm{Si}$ logramos mejorar la fabricación de adecuados zapatos para compensar la discapacidad funcional que la acompaña, no habrá razón para desecharla como una técnica salvadora que debe considerarse entre los procedimientos menores. Se toma la decisión de realizarla cuando hay importante pérdida de tejido de más de dos ortejos. No se concibe amputar tres dedos y no hacer la transmetatársica. Lo primero daría como resultado un pie disfuncional.

Me permito mencionar las pautas que se siguen en el Beth Israel Deaconess Medical Center para decidir realizar una amputación mayor: infracondílea (BKA: siglas para "Below Knee Amputación”) o supracondílea, (AKA: por "Above Knee Amputation"). Se hará amputación mayor cuando exista:

- Pérdida excesiva de tejidos.

- Importante isquemia que no pueda solucionarse con cirugía vascular.

- Incontrolable infección.

- Inhabilidad de reconstruir un pie funcional.

- Falta de cicatrización, a pesar de que el puente vascular está permeable.

Para finalizar, debo insistir en la importancia que tiene la rodilla para el paciente que puede ser rehabilitado. Actualmente, a diferencia de antaño, se recomienda cirugía vascular previa a la amputación, con miras exclusivamente a salvar esa articulación. Por desgracia no existe ningún examen que pueda predecir cómo cicatrizará una amputación por abajo o arriba de la rodilla.

Existe un procedimiento que es necesario valorar con cuidado: la amputación en guillotina para erradicar total y rápidamente la sepsis de un pie en un debilitado enfermo, al que se le practicará, unos pocos días más tarde, la definitiva amputación que le corresponda.

La amputación en el muslo debe efectuarse exclusivamente en pacientes en muy mal estado general, y en los se considera imposible una rehabilitación postoperatoria.

\section{Lecturas recomendadas}

1. Kozak GF. Management of Diabetic Foot Problems. 1984.

2. LoGerfo FW, Gibbons GW, Pomposelli FB, Campbell DR, Miller A, Freeman DV, Quist WC. Trends in the care of the diabetic foot. Expanded roll of arterial reconstruction. Arch Surg 1992; 127 (5): 617-20.

3. Wheat LJ, Allen SD, Henry M, Kernek CB, Siders JA, Kuebler T, et al. Diabetic foot infections. Bacteriologic analysis. Arch Intern.Med 1986; 146 (10): 1935-40.

4. Pfeifer MA, Schumer MP. Clinical trails of diabetic neuropathy: past, present, and future. Diabetes 1995; 44 (12): 1355-61.

5. Akbari CM, LoGerfo FW. Diabetes and peripheral vascular disease. J Vas Surg 1999; 30 (2): 373-84.

6. Pomposelli FB, Jepsen SJ, Gibbons GW, Campbell DR, Freeman DV, Gauchan BM, et al. A flexible approach to infrapopliteal vein grafts in patients with diabetes mellitus. Arch Surg 1991; 126 (6): 724-7. 